2014-11

\title{
Implicit meaning in 18-month-old toddlers
}

\author{
Delle Luche, C
}

http://hdl.handle.net/10026.1/9948

10.1111/desc. 12164

Developmental Science

Wiley

All content in PEARL is protected by copyright law. Author manuscripts are made available in accordance with publisher policies. Please cite only the published version using the details provided on the item record or document. In the absence of an open licence (e.g. Creative Commons), permissions for further reuse of content should be sought from the publisher or author. 


\title{
SHORT REPORT
}

\section{Implicit meaning in 18-month-old toddlers}

\section{Claire Delle Luche, ${ }^{1}$ Samantha Durrant, ${ }^{1}$ Caroline Floccia ${ }^{1}$ and Kim Plunkett ${ }^{2}$}

1. School of Psychology, Plymouth University, UK

2. Department of Experimental Psychology, University of Oxford, UK

\begin{abstract}
A substantial body of evidence demonstrates that infants understand the meaning of spoken words from as early as 6 months. Yet little is known about their ability to do so in the absence of any visual referent, which would offer diagnostic evidence for an adult-like, symbolic interpretation of words and their use in language mediated thought. We used the head-turn preference procedure to examine whether infants can generate implicit meanings from word forms alone as early as 18 months of age, and whether they are sensitive to meaningful relationships between words. In one condition, toddlers were presented with lists of words taken from the same taxonomic category (e.g. animals or body parts). In a second condition, words taken from two other categories (e.g. clothes and food items) were interleaved within the same list. Listening times were found to be longer in the related-category condition than in the mixed-category condition, suggesting that infants extract the meaning of spoken words and are sensitive to the semantic relatedness between these words. Our results show that infants have begun to construct the rudiments of a semantic system based on taxonomic relations even before they enter a period of accelerated vocabulary growth.
\end{abstract}

\section{Introduction}

From early in the course of development infants are proficient word recognizers (e.g. Fennell \& Werker, 2003; Swingley \& Aslin, 2000; Swingley \& Fernald, 2002), are able to identify the referent of some common nouns from as early as 6 months of age (Bergelson \& Swingley, 2012; Tincoff \& Jusczyk, 1999, 2011), and achieve adult-like speeds of decoding by the time they reach their second birthday (Fernald, Swingley \& Pinto, 2001). Spoken word recognition in young children is typically examined through the Intermodal Preferential Looking task (IPL; Golinkoff, Hirsh-Pasek, Cauley \& Gordon, 1987): infants hear a word while they look at a pair of pictures. Preferential fixation of a target picture indexes their understanding of the spoken word. In comparison, infants' understanding of a word's meaning in the absence of a visual referent has been overlooked. Yet a demonstration that they can access meaningful representations from words in the absence of any supporting visual stimuli would offer diagnostic evidence for an adult-like, symbolic interpretation of words and their use in language mediated thought. The mastery of this ability is a critical component for the rapid interpretation of continuous sequences of words, as experienced in everyday speech.

Recent research has demonstrated that 18-month-old infants implicitly activate the phonological form for familiar objects (Mani \& Plunkett, 2010). When presented with a prime image, e.g. a dog, 18-month-olds look longer at a phonologically related named target (e.g. door) than an unrelated one (e.g. boat). Implicit naming of objects in the infants' visual environment supports their interpretation of speech and highlights the commonalities between objects that share the same name (such as $d o g$ for many different varieties of dogs). In this research, we explore whether 18-month-olds can also, through the spoken word alone, extract its implicit meaning and so demonstrate a two-way link between word and object. Specifically, we examine whether the presentation of a spoken word triggers the activation of semantically related spoken words, without the 
mediation of an explicit pictorial representation. We focused on the conceptually driven taxonomic relationships between words in contrast to input driven associative relationships (which 'are acquired through association with different activities and through cooccurrence in the accompanying speech'; Brooks \& Kemper, 2012, p. 74). Words which are taxonomically related may be 'related through either classification or composition', classification being 'the relationship between a superordinate term and its members' (e.g. flu-pneumonia) and composition 'the part/whole relationship between lexical items which are meronyms or co-meronyms' (e.g. body-heart; Eggins, 2004, p. 43).

The age of 18 months often marks a milestone in lexical development as it is usually taken as the onset of a rapid acceleration in vocabulary learning (e.g. Mitchell \& McMurray, 2009), perhaps corresponding to a switch in the mode of acquisition (Nazzi \& Bertoncini, 2003), or to the necessary consequence of learning words in parallel combined with variations in the time needed to learn individual words (McMurray, 2007; Plunkett, Sinha, Møller \& Strandsby, 1992). Whatever the underlying mechanisms responsible for this rapid vocabulary growth, semantic links between words develop along with the expanding lexicon. From the age of 21 months, there is evidence of auditory-to-visual priming for semantically related but not unrelated word pairs (e.g. Arias-Trejo \& Plunkett, 2009; Styles \& Plunkett, 2009, 2011; Torkildsen, Syversen, Simonsen, Moen \& Lindgren, 2007). These findings suggest that toddlers begin to develop a structured lexicon, based on relationships between words and their related concepts. For example, Arias-Trejo and Plunkett (2013) presented infants either with pairs of words that were taxonomically related but associatively unrelated according to adult norms (e.g. $d o g-c o w)$ or word pairs that were associatively related but taxonomically unrelated (e.g. dog-bone). Both types of word pairs produced longer looking at a target picture as compared to unrelated word pairs at 24 months of age, indicating that toddlers are sensitive to both taxonomic and associative relationships between words. In contrast, at 21 months of age a priming effect is obtained only when words are taxonomically and associatively related.

This empirical finding is consistent with recent theoretical analyses of young children's vocabulary development, based on parental report, indicating that words are incorporated into semantic networks on the basis of shared perceptual (e.g. 'has wheels') and functional features (e.g. 'used for transportation'), providing a possible grounding for taxonomic relations (e.g. Hills, Maouene, Maouene, Sheya \& Smith, 2009). Failure to find priming effects at 18 months has been interpreted as suggesting the absence of a semantically structured lexicon during this early stage of lexical development prior to the onset of rapid vocabulary growth (AriasTrejo \& Plunkett, 2009; Styles \& Plunkett, 2009). However, any demonstration of semantic relationships between words as early as 18 months would help clarify the nature of the architecture of the emerging lexicon: the early lexicon might be a miniature version of the highly interconnected adult lexicon (e.g. Fodor, 1983), or early words might be processed only in their relation to objects or concepts, as if they were 'semantic islands' (Arias-Trejo \& Plunkett, 2009).

Experimental manipulations involving only auditory stimuli have led to significant progress in recent decades regarding infants' appreciation of the sound characteristics of words in their native language. The head-turn preference has been used, for example, to demonstrate infants' sensitivity to the prosodic and stress features of their language, syllabic transition probabilities and artificial grammar learning (Echols, Crowhurst \& Childers, 1997; Saffran, Aslin \& Newport, 1996; van Heugten \& Johnson, 2010). In this paradigm, infants are typically presented with a list of words played over a loudspeaker for as long as they maintain looking towards a flashing light which may be positioned either to their left or right (e.g. Gonzalez-Gomez \& Nazzi, 2011; Jusczyk, Cutler \& Redanz, 1993). Many studies have demonstrated that maintenance of attention to the sound-associated flashing light can be manipulated through properties of the auditory stimulus. Surprisingly perhaps, this technique has not been used to demonstrate early sensitivity to the meanings of words. Here we used the standard head-turn preference procedure to investigate whether 18-montholds are sensitive to semantic relations between words presented in lists. Some of the lists contained words that are related in meaning while other lists contained unrelated words. Since the relation between the sound of the word and its meaning is arbitrary, differences in maintenance of attention between the two types of list would indicate that infants are extracting the meanings of the words, and that they are sensitive to the semantic relations between them.

\section{Methods}

Children were presented with lists of spoken words taken from the same category (Related Categories condition or $\mathrm{RC}$ ) or from two categories and interleaved randomly (Mixed Categories condition or MC). Four categories were used altogether (animals, food, body parts and clothes) and each child was presented with all words from all four categories. In the RC condition (e.g. 
animals and clothes), they would hear a list of animals, then a list of clothes, then a list of animals, etc. In the MC condition (e.g. body parts and food), they would hear lists of body parts and food items randomly shuffled. Each child was presented with a block of six lists in the $\mathrm{RC}$ condition and six lists in the MC condition (with order counterbalanced).

\section{Participants}

Twenty-four children aged 18 months $(M=18 ; 3$, range $17 ; 10$ to $19 ; 3$; including 14 girls) were tested successfully, that is, completed each block with a minimum of four lists per block. Data from an additional nine infants were excluded because they did not understand at least $50 \%$ of the test words in each category according to the Oxford CDI (Hamilton, Plunkett \& Schafer, 2000). An additional two children were excluded because of extreme looking times leading to outlier differences between the two conditions (see also Bertoncini, Nazzi, Cabrera \& Lorenzi, 2011). Finally, a further 16 children did not complete the experiment due to fussiness $(n=12)$ or experimenter error $(n=4)$.

\section{Stimuli}

Four categories of objects were selected (food, clothes, animal, body parts), and eight words per category were chosen using the Oxford CDI (Hamilton et al., 2000), so that on average they would be known by $75 \%$ of 18 month-olds (Table 1).

The lists of words were balanced as much as possible in terms of linguistic complexity to ensure that children could not use low-level cues to distinguish the lists (e.g. Shi, Morgan \& Allopenna, 1998): number of syllables, stress pattern when relevant, vowel or consonant as initial phoneme, phonemic inventory (Table 2).

The degree of association between words within or across categories was estimated using the University of South Florida adult free association norms (Nelson, McEvoy \& Schreiber, 2004). The nature of the semantic link between words in related lists was most often purely taxonomic (e.g. horselmouse), but for some there was a mix of taxonomic and associative relations (e.g. cat/ mouse), a confound which was impossible to avoid entirely owing to the constraint of having to select words from a limited lexicon. In Nelson et al.'s (2004) norms, of the 32 words selected, eight never elicited any of the other words from the same or a contrasting taxonomic category (e.g. frog or tummy), nine elicited one other word within the same category (e.g. ear elicited nose), 10 elicited two words within and/or across categories (mouse elicited cheese and cat), four elicited three and one
Table 1 List of stimuli per semantic category with the percentage of children aged 18 months ( \pm 3 weeks, $N=207$ ) who understand or say a given word, extracted from the OCDI database (Hamilton et al., 2000). The column 'Current sample' corresponds to the percentage of children $(\mathrm{N}=24)$ who understood or said each word based on their individual OCDIs

\begin{tabular}{|c|c|c|c|c|c|}
\hline & OCDI & $\begin{array}{l}\text { Current } \\
\text { sample }\end{array}$ & & & $\begin{array}{l}\text { Current } \\
\text { sample }\end{array}$ \\
\hline animals & & & clothes & & \\
\hline $\operatorname{dog}$ & 98.1 & 100 & shoe & 98.6 & 100 \\
\hline cat & 93.7 & 91.2 & nappy & 92.3 & 100 \\
\hline cow & 83.1 & 100 & sock & 91.3 & 91.7 \\
\hline pig & 77.3 & 83.3 & hat & 87.4 & 83.3 \\
\hline horse & 75.4 & 75.0 & coat & 77.3 & 75.0 \\
\hline sheep & 68.6 & 66.7 & bib & 74.4 & 66.7 \\
\hline frog & 56.5 & 50.0 & trousers & 55.1 & 33.3 \\
\hline mouse & 54.6 & 16.7 & boots & 52.7 & 50.0 \\
\hline mean & 75.9 & 72.9 & mean & 78.6 & 75.0 \\
\hline body parts & & & food & & \\
\hline nose & 93.7 & 100 & biscuit & 88.4 & 83.3 \\
\hline tummy & 83.1 & 83.3 & milk & 87.4 & 100 \\
\hline ear & 83.1 & 75.0 & apple & 75.4 & 83.3 \\
\hline finger & 81.6 & 83.3 & bread & 71.5 & 58.3 \\
\hline mouth & 75.4 & 100 & juice & 71.5 & 41.7 \\
\hline teeth & 74.9 & 50.0 & toast & 69.1 & 83.3 \\
\hline toe & 70.5 & 75.0 & cheese & 63.3 & 91.7 \\
\hline arm & 56 & 66.7 & cake & 53.6 & 75.0 \\
\hline mean & 77.3 & 79.2 & mean & 75.5 & 77.1 \\
\hline
\end{tabular}

elicited four words within and/or across categories. The median associations per word was one, with an average elicitation probability of 0.12 (when given one of these words, adults are likely to elicit an associatively related word from our sample $12 \%$ of the time). Lists were constructed in such a way that two words with a potential associative link (e.g. mouse/cat or mouse/cheese) never occurred consecutively.

Words were recorded in an enthusiastic manner by a South-West of England native female speaker and normalized for amplitude using Praat (Boersma, 2001). Their mean duration was $700.2 \mathrm{~ms}$ (STD $109.6 \mathrm{~ms})$, with no difference across the four categories $(F(3,29)<1)$. Pseudo-randomized lists were created for each category or mixture of categories. In the RC condition, for each category six pseudo-randomized lists were created, so that the sequential position of each word within the list was not repeated more than twice. Words with an associative link could never appear consecutively (e.g. mouse/cat). The same criteria were used to generate 12 MC lists, with the following added constraints. The eight words in each category were divided in two sets of four (set A and set B). Then, for each possible pairing of categories (e.g. animal-clothes), half of the lists would contain the four animal names from set $\mathrm{A}$ and the four clothes items from set A. The other half would be made of the four animal names from set B and the four clothes 
Table 2 For each list of eight stimuli, mean of the following measures: number of monosyllabic words, number of disyllabic words, number of phonemes per word, number of vowel-initial words, number of words starting with a plosive or with a fricative (the most common categories), and number of different syllabic structures (CVC, CCVC, etc.). The first four rows correspond to the RC lists and the next 12 correspond to the MC condition. A child can be presented with two lists from the RC condition (e.g. animals and food), and with the two lists from clothes and body parts (list $A$ and list B)

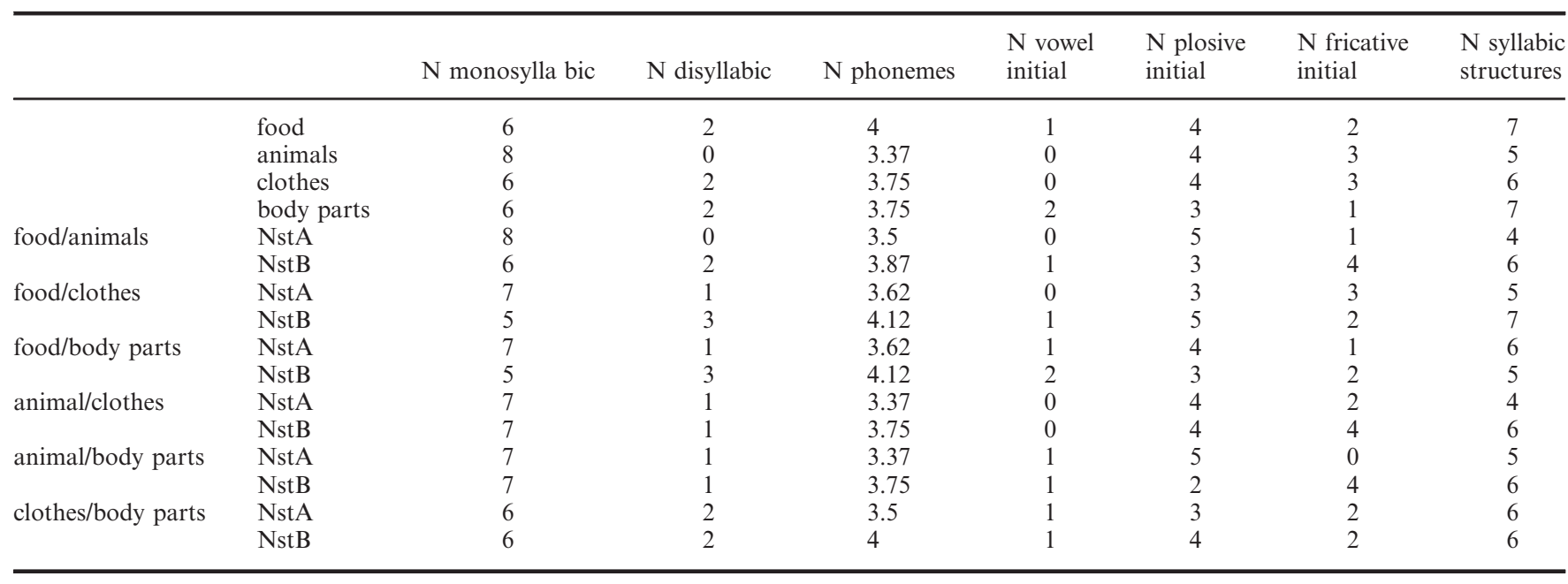

items from set $\mathrm{B}$. This was to ensure that in each condition ( $\mathrm{RC}$ or $\mathrm{MC}$ ), children would be presented with lists all containing eight different words. In addition, in the MC condition there could be no more than two consecutive words from the same category: for example, in the animal-clothes combination, a possible sequence within a list could be nappy-boots-cow-hat but not nappy-boots-hat-cow. Figure 1 shows an example of lists heard by one particular child who started in the $\mathrm{RC}$ condition (animals and food) followed by the MC condition (clothes and body parts). Because words in $\mathrm{RC}$ lists were taxonomically related, any difference in looking time to the MC lists would indicate that children implicitly activated the links within the superordinate, semantic categories.

Within each list, the eight words were concatenated with an ISI of $400 \mathrm{~ms}$ and the resulting lists were repeated three times to create sound files averaging 26.11 $\mathrm{s}$ for both the $\mathrm{RC}$ and the $\mathrm{MC}$ conditions.

Within each condition, the order of presentation of the six lists was randomized, together with the side of presentation, so that no more than two consecutive lists would be presented on the same side, and no more than two consecutive lists belonged to the same category. For the $\mathrm{RC}$ condition, each child was presented with three randomly chosen lists out of six in one category (e.g. animals) and three out of six lists in another category (e.g. clothes). For the MC condition, each child was presented with six randomly chosen lists out of the 12 possible lists of the corresponding condition (e.g. body parts and food). Crucially, each child was presented with
Related Category condition first - animals/food

\begin{tabular}{ll|l|l|}
\hline I DOG & -1 & biscuit \\
I PIG & I & milk \\
I CAT & I & apple \\
I SHEEP & I & cheese \\
I HORSE & I & juice \\
I MOUSE & I & bread \\
I COW & I & cake \\
I FROG & I & toast \\
I & $\ldots$ & I & ...
\end{tabular}

\begin{tabular}{|l|}
\hline CAT \\
COW \\
SHEEP \\
PIG \\
DOG \\
MOUSE \\
FROG \\
HORSE \\
\hline.. \\
\hline
\end{tabular}

\begin{tabular}{|c|c|c|}
\hline $\bar{I}_{\text {milk }}-1$ & apple & I $\overline{\text { HORSE }}$ \\
\hline I biscuit I & milk & I SHEEP \\
\hline I toast I & toast & I FROG \\
\hline I apple & juice & I MOUSE I \\
\hline I bread & bread & cow \\
\hline cake & cheese & DOG \\
\hline I cheese I & biscuit & PIG \\
\hline j juice & cake & I CAT \\
\hline I & ... & L \\
\hline
\end{tabular}

Mixed Category condition second - clothes/body parts

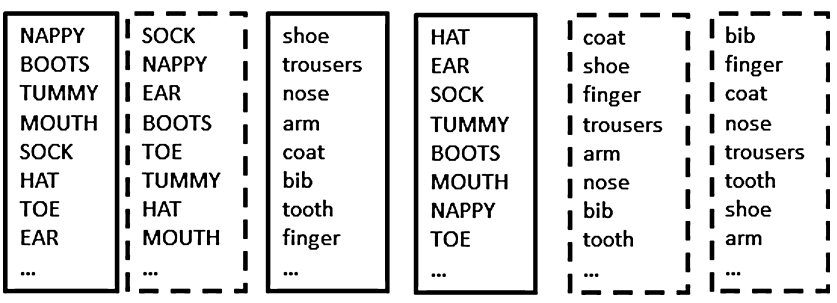

Figure 1 Example of the lists of words heard by one child presented with the Related-Categories condition first (above) followed by the Mixed-Categories condition (below). In the RC block, three lists are made of eight animal names (upper case) and three lists are made of eight food items (lower case). In the MC block, all lists are made of a mix of clothes and body parts, but half of them contain four clothes items (nappy, boots, sock, hat) and four body parts (tummy, mouth, toe, ear). These lists are written in upper case letters. The other three lists contain four different clothes items (shoe, trousers, coat, bib) and four different body parts (nose, arm, tooth, finger); these are written in lower case letters. Dashed lines correspond to lists presented on the left hand side of the child and plain lines to lists presented on her right. 
all four categories, two were used in the RC condition, and the other two were used in the MC condition (Figure 1). Across all children, each category would appear as often in the RC and the MC condition, and each pairing of categories was equally represented. Out of 24 children, in the RC condition lists of food items were presented 12 times, but due to an experimenter error, lists of clothes and body parts were presented 13 times, and lists of animals 10 times.

Half of the children were presented with the RC condition first followed by the MC condition, and the other half heard the reverse order.

\section{Procedure}

After two training trials during which the children heard a piece of music (to ensure they understood that sounds could emanate from the left or the right when they looked towards the corresponding light), each child was presented with a first block of six lists, and following a short break, with a second block of six new lists. For example, a child tested in the MC condition first would hear a block of six lists of words from the clothes and food categories mixed together. After a short break, a second block of six lists would follow, composed of words from the body parts and animals categories ( $\mathrm{RC}$ condition), so that three lists would be made of animal names only, and three lists would be made of body part names only. Any looking time shorter than $1.5 \mathrm{~s}$ on one list would automatically result in the termination of that list and the list being repeated immediately (with the original looking times discarded). Any look away from the light for more than $2 \mathrm{~s}$ would result in the termination of the list and the re-centring of attention with the central light.

\section{Results}

Looking times shorter than $2 \mathrm{~s}$ were eliminated from the analyses, since to detect the semantic structure of the lists, children needed a minimum of two consecutive words (see also Gómez \& Maye, 2005), which could not occur in less than 2 seconds for each list. With this criterion, children completed an average of 5.8 lists (out of 6) in the RC condition, and 5.9 lists in the MC condition. Looking times in each condition were normally distributed across all children (Shapiro-Wilk W test, $\mathrm{W}=.99, p=.97$ in $\mathrm{RC} ; \mathrm{W}=.97, p=.56$ in $\mathrm{MC}$ ). An ANOVA with Condition (MC or RC) as a withinparticipant factor and Order (starting with the $\mathrm{MC}$ or $\mathrm{RC}$ condition) as a between-participant factor was conducted on mean looking times. Order did not have

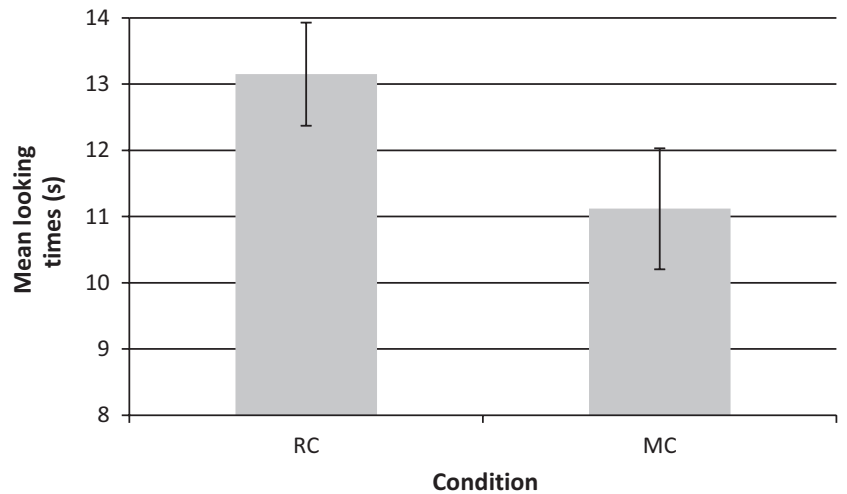

Figure 2 Mean looking times (with standard errors) towards the sound source (in s) as a function of condition (RC versus $\mathrm{MC})$.

any significant effect $(F(1,11)<1)$, neither did it interact with Condition $\left(F(1,22)=1.21, p=.28, \eta^{2}=.05\right)$. Therefore it was not included in further analyses. Overall, children listened longer to lists in the RC condition $(13.15 \mathrm{~s}, S D=3.81)$ than in the MC condition $\left(11.12 \mathrm{~s}, S D=4.47, F(1,23)=6.11, p=.021, \eta^{2}=.21\right)$ (Figure 2). ${ }^{1}$ Seventeen out of 24 children showed this pattern of response (exact binomial test, $p=.021$ ).

Children had an average OCDI score in production of 73.1 words (out of $416 ; S D=68.2$ ) and 233.3 words in comprehension $(S D=73.5)$. Comprehension scores were normally distributed (Shapiro-Wilk $\mathrm{W}$ test, $\mathrm{W}=.97$, $p=.61$ ), but not for production ( $\mathrm{W}=.84, p=.002)$, probably because of a floor effect. These scores were compared with each child's listening time in the RC and the MC conditions, using Pearson correlation for comprehension and Spearman non-parametric correlation for production scores. A marginally significant correlation between the OCDI comprehension score and listening times in the RC condition was found (Pearson $r(24)=.40, p=.053)$, indicating that the more words children understood overall, the longer they listened to words organized according to their semantic categories. No other correlation was significant.

To further investigate the link between vocabulary knowledge and looking times, we ranked the children as a function of the proportion of the test words that they could produce and divided them into two 12-children 'Talker' groups. The first group understood on average $85 \%$ of the words but produced only $9.9 \%$; the second group understood $91 \%$ and produced $62.5 \%$ of the words. An ANOVA with Condition (RC vs. MC) as a

\footnotetext{
${ }^{1}$ When all 33 children are included in the data $(24+9$ with low CDI scores) the results are similar: significantly longer looking times in $\mathrm{RC}$ $(12.4 \mathrm{~s})$ than $\mathrm{MC}\left(10.9 \mathrm{~s} ; F(1,32)=4.45, p=.043, \eta^{2}=.12\right)$.
} 
repeated measure and Talker group as a betweenparticipant factor revealed no interaction between Condition and Talker $(F(1,22)<1)$ and no main effect of Talker group $(F(1,22)<1)$.

\section{Discussion}

When 18-month-olds listen to word lists consisting of names of objects taken from the same taxonomic category, they maintain their 'listening times' longer than if the words were selected from different categories. This impact of list type could only occur if the children were computing the meanings of the words as they were listening to them. That they attended longer to lists containing related words than words belonging to two categories is consistent with a priming interpretation of the results: related words prime one another (e.g. Meyer \& Schvaneveldt, 1971) and prompt longer listening whereas unrelated words do not. These results are also consistent with findings from cross-modal priming studies with young children where a pair of taxonomically related words produces longer looking at a target picture than a pair of unrelated words (Arias-Trejo \& Plunkett, 2009, 2013).

In fact, these results demonstrate not only that young children compute the meanings of words from hearing the spoken word alone but that they are sensitive to the relationships between word meanings. It is indeed their sensitivity to taxonomic relations between words which indicates that they must have computed the meaning of words. The current study is the first to suggest that the sensitivity to a semantic link between spoken words is present as early as 18 months of age. Our findings point to the conclusion that infants construct a semantic network during the early stages of lexical development.

The ability to detect the presence of any implicit taxonomic relationships between words seems to be stronger with increasing receptive vocabulary, as indexed by the correlation between OCDI scores and listening times in the related condition. One possible explanation of this correlation is that children with larger vocabularies process words at a faster rate than children with smaller vocabularies (Fernald, Pinto, Swingley, Weinberg \& McRoberts, 1998). Rapid word processing should facilitate access to word meaning and subsequent computations of the similarity in meaning between consecutive words. Words are presented at a rapid rate in the current experiment - approximately one per second (700 $\mathrm{ms}$ for the word and an ISI of $400 \mathrm{~ms}$ ). Within that second, infants must both recognize the word and compute some aspects of its meaning, in order to discriminate between related and mixed lists. However, further research is needed to determine the underlying source of the correlation, whether it be processing speed, or semantic links growing stronger with the increasing lexicon size, or whether a larger lexicon allows children to perform better in the task due to their knowledge of more test words.

It is noteworthy that we found no evidence of a link between word production abilities and semantic processing. When children start producing words, their familiarity and experience with these words increase, changing the way these words (and new words) are represented and processed. For example, Mills, Plunkett, Prat and Schafer (2005) showed increased cerebral specialization in brain activity for newly learnt words in children scoring higher on the OCDI in production than those scoring lower. Similarly, DePaolis, Vihman and KerenPortnoy (2011) showed that infants aged 18 months pay more attention to speech samples containing consonants that they produce themselves. In contrast, the current study suggests that only receptive knowledge of words drives infants' semantic relationships between words.

It was important to establish that the underlying relationship between words in the $\mathrm{RC}$ condition was not merely associative. Otherwise, longer looking times in the $\mathrm{RC}$ vs. the MC condition need not reflect computation of meaning since pure linguistic context/collocational information could be driving the observed effects. It is true that taxonomically related words can also be associatively related $(c a t-d o g)$. However, by minimizing the impact of associative relations in this study, we can be more confident that differences between our experimental conditions are driven by the computation of underlying meaning. Although in the design of the experiment we strived to eliminate any associative relations between consecutive words in each list, we cannot completely discount the possibility that prior experience of hearing these words uttered together might have contributed to our pattern of findings. Indeed, we used adult association norms to estimate the strength of associations - the only ones available to date, which might not accurately reflect children's experience with words. As 18-montholds have a much smaller lexicon than adults, the strength of associations between the few words they know might be stronger than in adults.

Hills (2012) has argued that infant-directed speech during the first few years of life is more associative than adult-directed speech, i.e. the probability that a target word is produced within a five-word window of an associative cue is higher in infant-directed corpora than in adult-directed corpora. This could support the proposal that the structure of the early lexicon is based mainly on associative relationships, from which later taxonomic relations would be derived (e.g. Nelson, 
1985). Arias-Trejo and Plunkett (2013) report pure taxonomic priming $(\operatorname{dog}-\mathrm{cow})$ and pure associative priming (dog-bone) in 24-month-olds, indicating that both of these types of relationship between words underpin the structure of the infant lexicon. However, their results indicate that neither pure taxonomic nor pure associative relationships yield priming effects at 21 months, in contrast with an earlier study demonstrating that words that are both taxonomically and associatively related $(\operatorname{dog}-c a t)$ prime each other at 21 months (Arias-Trejo \& Plunkett, 2009). These authors argue that the pattern of results across the two studies points to a role for both taxonomic and associative relationships in the emergence of structure in the infant lexicon as early as 21 months of age.

Failure to detect any trace of taxonomic priming in previous studies with 18-month-olds (Arias-Trejo \& Plunkett, 2009, 2013; Styles \& Plunkett, 2009, 2011) stands in stark contrast to the behaviour of the 18month-olds in the current study, and raises the question as to the source of the difference in behaviours. The earlier priming studies drew upon a similar set of vocabulary items as the current study, and all studies used participants drawn from a southern British English population. Perhaps most importantly, both sets of studies required infants to demonstrate an appreciation of the meaning of words and the relationships between them. We suggest that the contrasting methodologies offer a source of explanation for the differing results. The cross-modal priming studies required infants to process both auditory and complex visual stimuli whereas the version of the head-turn preference procedure used in the current study required infants to attend to similar auditory stimuli and simple flashing lights. Processing of the complex visual stimuli in the cross-modal procedure may have imposed additional perceptual and/or cognitive loads on the infants (e.g. activation of common and different features) and masked potential priming effects (see Mather \& Plunkett, 2011; Plunkett, 2010; Robinson \& Sloutsky, 2007; Stager \& Werker, 1997, for related arguments), thereby underestimating their sensitivity to intra-word relationships.

In conclusion, previous research has shown that 18month-olds can implicitly name familiar objects (Mani \& Plunkett, 2010). The current research demonstrates that not only do infants understand words in the absence of visual support; moreover, they recognize the similarity in meaning of consecutive words. Together, these findings suggest that the functional pathway between the young child's mental representations of words and objects is a two-way street along which listening and seeing interact with each other. The dynamics of this interaction in the young child have yet to be determined. However, it is apparent from these laboratory experiments that in the everyday world very young children have the capacity to compute complex meaningful relationships between words, even in the absence of the objects to which they refer, enabling them to make sense of what people are saying.

\section{References}

Arias-Trejo, N., \& Plunkett, K. (2009). Lexical-semantic priming effects during infancy. Philosophical Transactions of the Royal Society, B, 364, 3633-3647.

Arias-Trejo, N., \& Plunkett, K. (2013). What's in a link: associative and taxonomic priming effects in the infant lexicon. Cognition, 128 (2), 214-227.

Bergelson, E., \& Swingley, D. (2012). At 6-9 months, human infants know the meanings of many common nouns. Proceedings of the National Academy of Sciences, USA, 109 (9), 3253-3258.

Bertoncini, J., Nazzi, T., Cabrera, L., \& Lorenzi, C. (2011). Six-month-old infants discriminate voicing on the basis of temporal envelope cues. Journal of the Acoustical Society of America, 129, 2761-2964.

Boersma, P. (2001). Praat, a system for doing phonetics by computer. Glot International, 5 (9/10), 341-345.

Brooks, P., \& Kemper, V. (2012). Language development. Chichester: John Wiley \& Sons.

DePaolis, R.A., Vihman, M.M., \& Keren-Portnoy, T. (2011). Do production patterns influence the processing of speech in prelinguistic infants? Infant Behavior and Development, 34 (4), 590-601.

Echols, C.H., Crowhurst, M.J., \& Childers, J.B. (1997). The perception of rhythmic units in speech by infants and adults. Journal of Memory and Language, 36 (2), 202-225.

Eggins, S. (2004). Introduction to systemic function linguistics (2nd edn.). London: Continuum International Publishing Group.

Fennell, C.T., \& Werker, J.F. (2003). Early word learners' ability to access phonetic detail in well-known words. Language and Speech, 46 (2-3), 245-264.

Fernald, A., Pinto, J.O., Swingley, D., Weinberg, A., \& McRoberts, G.W. (1998). Rapid gains in speed of verbal processing by infants in the second year. Psychological Science, 9 (3), 228-231.

Fernald, A., Swingley, D., \& Pinto, J.P. (2001). When half a word is enough: infants can recognize spoken words using partial phonetic information. Child Development, 72 (4), 1003-1015.

Fodor, J. (1983). Representations: Philosophical essays on the foundations of cognitive science. Cambridge, MA: MIT Press/ Bradford Books.

Golinkoff, R.M., Hirsh-Pasek, K., Cauley, K.M., \& Gordon, L. (1987). The eyes have it: lexical and syntactic comprehension in a new paradigm. Journal of Child Language, 14, 23-45.

Gómez, R., \& Maye, J. (2005). The developmental trajectory of nonadjacent dependency learning. Infancy, 7 (2), 183-206. 
Gonzalez-Gomez, N., \& Nazzi, T. (2011). Acquisition of nonadjacent phonological dependencies in the native language during the first year of life. Infancy, 17 (5), 498-524.

Jusczyk, P.W., Cutler, A., \& Redanz, N. (1993). Preference for the predominant stress patterns of English words. Child Development, 64, 675-687.

Hamilton, A., Plunkett, K., \& Schafer, G. (2000). Infant vocabulary development assessed with a British Communicative Development Inventory: lower scores in the UK than the USA. Journal of Child Language, 27, 689-705.

Hills, T.T. (2012). The company that words keep: comparing the statistical structure of child-versus adult-directed language. Journal of Child Language, 1 (1), 1-19.

Hills, T.T., Maouene, M., Maouene, J., Sheya, A., \& Smith, L.B. (2009). Longitudinal analysis of early semantic networks: preferential attachment or preferential acquisition? Psychological Science, 20, 729-739.

McMurray, B. (2007). Defusing the childhood vocabulary explosion. Science, 317 (5838), 631.

Mani, N., \& Plunkett, K. (2010). In the infant's mind's ear: evidence for implicit naming in 18-month-olds. Psychological Science, 21 (7), 908-913.

Mather, E., \& Plunkett, K. (2011). Same items, different order: effects of temporal variability on infant categorization. Cognition, 119 (3), 438-447.

Meyer, D.E., \& Schvaneveldt, R.W. (1971). Facilitation in recognizing pairs of words: evidence of a dependence between retrieval operations. Journal of Experimental Psychology, 90 (2), 227-234.

Mills, D.L., Plunkett, K., Prat, C., \& Schafer, G. (2005). Watching the infant brain learn words: effects of vocabulary size and experience. Cognitive Development, 20 (1), 19-31.

Mitchell, C., \& McMurray, B. (2009). On leveraged learning in lexical acquisition and its relationship to acceleration. Cognitive Science, 33 (8), 1503-1523.

Nazzi, T., \& Bertoncini, J. (2003). Before and after the vocabulary spurt: two modes of word acquisition? Developmental Science, 6 (2), 136-142.

Nelson, K. (1985). Making sense: The acquisition of shared meaning. Orlando, FL: Academic Press.

Nelson, D.L., McEvoy, C.L., \& Schreiber, T.A. (2004). The University of South Florida free association, rhyme, and word fragment norms. Behavior Research Methods, Instruments, \& Computers, 36 (3), 402-407.

Plunkett, K. (2010). How labels impact infant categorisation. In L. Oakes, C.H. Cashon, M. Casasola \& D.H. Rakison (Eds.), Infant perception and cognition: Recent advances, emerging theories, and future directions. New York: Oxford University Press.

Plunkett, K., Sinha, C.G., Møller, M.F., \& Strandsby, O. (1992). Symbol grounding or the emergence of symbols? Vocabulary growth in children and a connectionist net. Connection Science, 4, 293-312.

Robinson, C.W., \& Sloutsky, V.M. (2007). Visual processing speed: effects of auditory input on visual processing. Developmental Science, 10 (6), 734-740.

Saffran, J.R., Aslin, R.N., \& Newport, E.L. (1996). Statistical learning by 8-month-old infants. Science, 274 (5294), 1926-1928.

Shi, R., Morgan, J.L., \& Allopenna, P. (1998). Phonological and acoustic bases for earliest grammatical category assignment: a cross-linguistic perspective. Journal of child Language, 25 (01), 169-201.

Stager, C.L., \& Werker, J.F. (1997). Infants listen for more phonetic detail in speech perception than in word-learning tasks. Nature, 388 (6640), 381-382.

Styles, S., \& Plunkett, K. (2009). How do infants build a semantic system? Language and Cognition, 1, 1-24.

Styles, S., \& Plunkett, K. (2011). Early links in the early lexicon: semantically related word pairs prime picture looking in the second year. In M.G. Gaskell \& P. Zwitserlood (Eds.), Lexical representation: A multidisciplinary approach (pp. 51-88). Berlin/New York: De Gruyter Mouton.

Swingley, D., \& Aslin, R.N. (2000). Spoken word recognition and lexical representation in very young children. Cognition, 76 (2), 147-166.

Swingley, D., \& Fernald, A. (2002). Recognition of words referring to present and absent objects by 24-month-olds. Journal of Memory and Language, 46 (1), 39-56.

Tincoff, R., \& Jusczyk, P.W. (1999). Some beginnings of word comprehension in 6-month-olds. Psychological Science, 10 (2), 172-175.

Tincoff, R., \& Jusczyk, P.W. (2011). Six-month-olds comprehend words that refer to parts of the body. Infancy, 17 (4), 432-444.

Torkildsen, J.v.K., Syversen, G., Simonsen, H.G., Moen, I., \& Lindgren, M. (2007). Electrophysiological correlates of auditory semantic priming in 24-month-olds. Journal of Neurolinguistics, 20 (4), 332-351.

van Heugten, M., \& Johnson, E.K. (2010). Linking infants' distributional learning abilities to natural language acquisition. Journal of Memory and Language, 63 (2), 197-209.

Received: 8 May 2013

Accepted: 12 November 2013 